\title{
Surface Pre-Ignition Measurements of Fuel Components and Their Mixtures
}

\author{
Johannes Mutzke \& Richard Stone; University of Oxford \\ John Williams; BP International
}

\begin{abstract}
A closed loop temperature controlled glow-plug has been used to control the incidence of surface pre-ignition of n-pentane, iso-pentane, n-heptane, iso-octane, ethanol, cyclohexane, ethyl-benzene, toluene and xylene, and four representative mixtures of these components. Statistical data on the incidence of pre-ignition compared with spark ignition has been derived from the in-cylinder maximum pressure, and the glow-plug temperature has been characterised on a cycle-by-cycle basis.
\end{abstract}

The alkanes and alcohols were found to be rather susceptible to surface pre-ignition, with the straight chained molecules having a higher pre-ignition tendency than branched chain molecules. The pre-ignition tendency of ring-structured components depends on the length of the attached chain, with shorter side-chain molecules (xylene, toluene) being less susceptible to pre-ignition than longer side-chain molecules like ethyl-benzene; cyclohexane was more susceptible to pre-ignition than any of the aromatic fuels. A higher glow-plug temperature was found to be needed for pre-igniting stoichiometric or rich mixtures, and this was attributed to the weaker mixture having a higher compression index and a lower specific heat capacity.

Keywords: pre-ignition; abnormal combustion; fuel components

\section{Introduction}


Pre-ignition means ignition prior to the occurrence of the ignition spark, and in the past this was only associated with surface ignition. However, now it often refers to ignition in the bulk of the compressed unburned mixture, caused by the auto-ignition of, for example, a lubricant droplet. A recent comprehensive review by Wang et al [1] discusses this form of auto-ignition and the related phenomenon of 'super knock'. Conventionally, pre-ignition referred to the ignition of the fuel/air mixture by a hot spot such as a part of the spark plug, combustion deposits or an exhaust valve, so this is termed 'surface pre-ignition' in the title here, so as to avoid any ambiguity. The maximum pressures observed during pre-ignition are higher and occur earlier than during normal combustion as the earlier start of the combustion compresses the end gas more [2,3]. Evidence that different mechanisms are involved in surface preignition and auto-ignition in the bulk gas is provided by the absence of a correlation between octane rating and surface pre-ignition ratings [4].

Combustion analysis of surface pre-igniting cycles has shown that flames appeared before the spark ignition timing, and this has been confirmed in optical and flame ionization studies. The rate of the heat release is in the same range as during normal spark ignition experiments which is significantly below the heat release rate during auto-ignition that is associated with combustion 'knock'. This also shows that surface pre-ignition and auto-ignition are distinct phenomena [3-5]. The high rate of heat release rate during auto-ignition is because with 'knock' a significant quantity of mixture has been compressed to a high temperature and is at the point of combusting.

The increased pressure during surface pre-igniting cycles leads to magnified negative work during the compression stroke, and this can reduce the efficiency in an engine. The earlier ignition means that all pressures during combustion are increased, so the pressure in the unburned gas will be higher along with its temperature. The raised unburned gas temperature 
can lead to auto-ignition of the remaining unburned gas and a very rapid pressure rise that leads to audible knock. The rapid pressure rise is also associated with an increased heat flux so component temperatures will rise. If the auto-ignition was a consequence of pre-ignition, then the higher component temperatures will mean earlier pre-ignition and thence earlier and more intense auto-ignition. This leads to runaway knock and the likelihood of structural damage to the engine; turning off the spark ignition will, of course, have no benefit.

Surface pre-ignition can only occur if two criteria are met: the ignition criterion and the propagation criterion. The ignition criterion states that there must be a source of ignition present in the engine. The initiation criterion dictates that after ignition, a flame must grow to a critical size in order to propagate further when the ignition source (e.g. the hotspot) has disappeared. The hot spot has to provide enough energy for the flame kernel to reach this critical size. If the flame size is too small, the rate of heat loss to the surroundings outweighs the rate of heat release from the chemical reaction and the flame extinguishes. The influence of the pressure and temperature on the laminar burning velocity and how these impact on preignition have been discussed comprehensively by Kalghatgi [4], who concludes that slow burning fuels are less prone to pre-ignition.

The most comprehensive data on the pre-ignition properties of pure fuel components is the work of Downs and Theobald [3] who tested 21 components. This work is now over 50 years old and did not have the benefit of modern data acquisition systems that allow statistical analysis of data from many engine cycles. As pre-ignition is a highly stochastic process, then this placed high demands on the test operator in determining a threshold for pre-ignition. This work also ranked the resistance to pre-ignition in terms of the heat input to a glow-plug, which then makes comparisons with other data very difficult. They also provided data on the temperature of their heater which will be discussed later. Recent work by Budak et al [6] have also used a heater plug but in a boosted gasoline direct injection engine with an emphasis on 
testing biofuels. Their threshold for pre-ignition was set at 2 per cent with their thermocouple temperature measurements being mean values.

There are different ways of inducing surface pre-ignition and reporting the susceptibility of a fuel to surface pre-ignition. Guibet and Duval [7] used two methods: a heating element, and spark plugs with different temperature ratings, and in both cases temperature was used to characterise the pre-ignition ratings. A particular interest was how the metallic additives in oil and fuel led to deposits that catalysed pre-ignition, and these effects were quantified by how long the engine had to be run before pre-ignition occurred.

Menrad et al [8] also used spark plugs with different heat ratings and materials to quantify the pre-ignition rating of different alcohol gasoline blends with a particular focus on methanol (because of its susceptibility to pre-ignition). They used the spark plug as an ionisation detector so could determine whether or not pre-ignition had occurred. They increased the temperature of the sparkplug by retarding the ignition timing and reported their results in terms of this critical ignition timing.

Another approach to identifying a pre-igniting cycle is reported by Luef et al [9] who considered the angle of occurrence of the $5 \%$ mass fraction burned $(\mathrm{mfb})$ in 200 consecutive cycles . If the observed $5 \% \mathrm{mfb}$ is earlier than a predefined limit (which was set at two times the standard deviation of the $5 \% \mathrm{mfb}$ point earlier than the mean value for spark-ignited combustion) then pre-ignition has occurred. The compression ratio was then adjusted to find the value that would satisfy their pre-ignition criterion. Tests with a similar pre-ignition criterion were also undertaken with a heated glow-plug and the temperature for pre-ignition was reported for a range of alcohols blended with iso-octane. 


\section{Experimental Equipment and Procedure}

As with the work of Downs and Theobald [3] a Ricardo E6 variable compression ratio engine has been used for the surface pre-ignition tests; it has a bore of $76 \mathrm{~mm}$ and a stroke of $111 \mathrm{~mm}$. The inlet valve opens $9^{\circ} \mathrm{bTDC}$ and closes $37^{\circ} \mathrm{aBDC}$; the exhaust valve opens $41^{\circ} \mathrm{bBDC}$ and closes $6^{\circ}$ aTDC. The engine (Figure 1) has two M14x1.25 tapped holes on opposite sides of the cylinder head: one being used for a spark plug fitted with a Kistler 6051A piezo-electric pressure transducer, and the second being used for the pre-ignition glow-plug and thermocouple. An NGK Y-307R diesel glow-plug was mounted in a holder that had a leadthrough for the type $\mathrm{K}$ thermocouple that was butt-welded onto the surface of the glow-plug. A NI USB-6525 card with LabVIEW was used to record the temperature of the glow-plug; the power to the glow-plug was regulated by a MOSFET that was controlled by a PID controller within LabVIEW

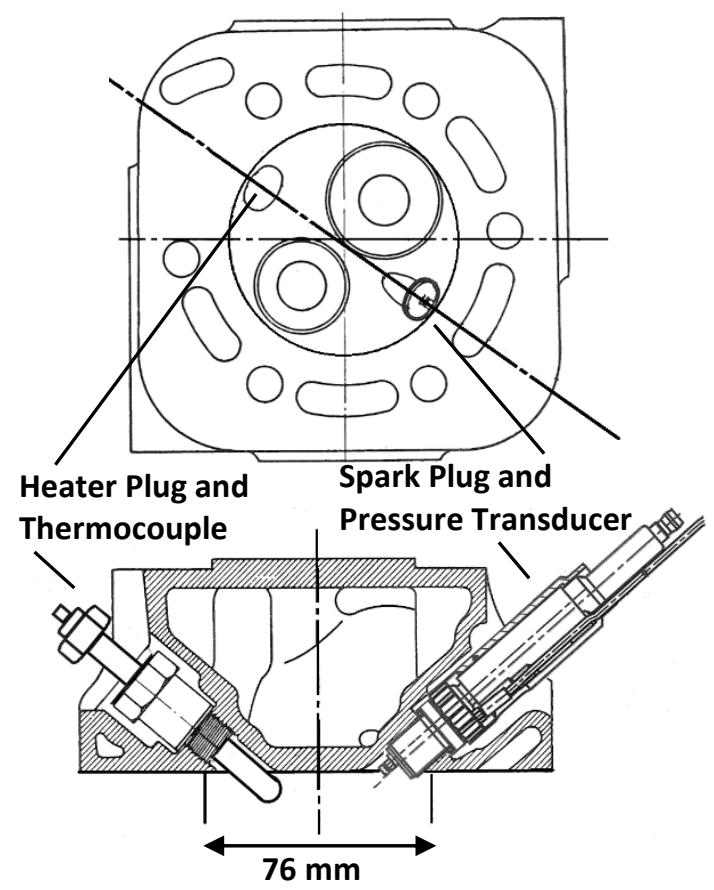

Fig 1 Cross-section and plan view of the cylinder head showing the heater plug and thermocouple, and the spark plug with integral pressure transducer, adapted from Ricardo and Hempson [2].

The engine was comprehensively instrumented with thermocouples, flow sensors, pressure transducer and other sensors described later. The instrumentation was connected to two NI 
USB-6211 data acquisition cards (maximum sampling rate of $250 \mathrm{ksamples} / \mathrm{s}$ ) for once per cycle and once per degree crank angle measurements. Typically over 500 cycles of data were recorded with the engine operating at wide open throttle. Data acquisition was through a LabVIEW program that also provided closed loop control of the air temperature (set at $30^{\circ} \mathrm{C}$ ), coolant temperature (set at $80^{\circ} \mathrm{C}$ ) and lambda (using the signal from an Innovate LM-1 lambda sensor system to control the port fuel injector). Data acquisition was controlled by an incremental shaft encoder (360 ppr), that also enabled the LabVIEW system to set the ignition timing. The engine was equipped with a port fuel injector and 3 fuel tanks pressurised with nitrogen; solenoid valves enabled the operation to be readily switched between the different fuels. The compression ratio was measured by an LVDT that had been calibrated against a micrometer. The engine speed was regulated to $600 \mathrm{rpm}$ by the DC dynamometer and a load cell was used to measure the torque.

The pre-ignition experiments were conducted with a spark-ignition timing of $5^{\circ} \mathrm{ca}$ bTDC. This retarded timing was selected so that when pre-ignition occurred it would not immediately lead to knock. Various criteria based on combustion analysis derived from the pressure record were considered (such as the angle at which 50\% mass fraction burned occurred or values of the heat release rate), but it was concluded that these had no advantage over the most direct measurement - the maximum cylinder pressure. Even with the maximum cylinder pressure there are different criteria that can be used.

Figure 2 shows histograms of $P_{\max }$ at different glow-plug temperatures with iso-octane, operating at the stoichiometric air fuel ratio and a compression ratio of 6 . 

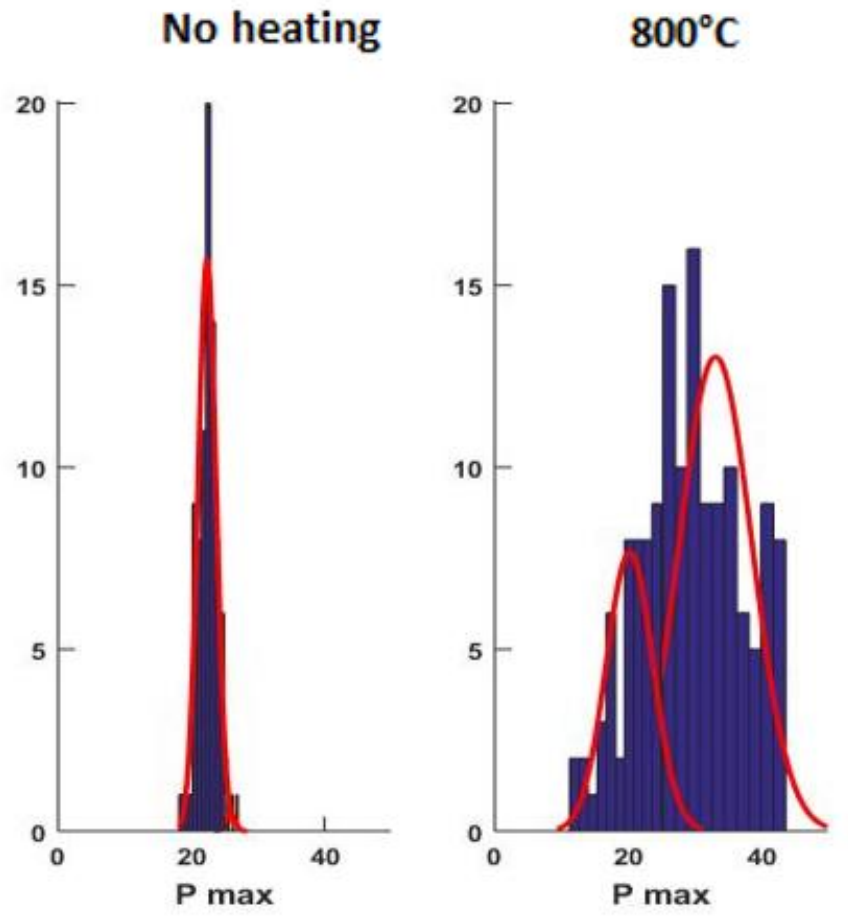

Fig 2 Histograms of the maximum cylinder pressure $\left(P_{\max }\right)$ at different glow-plug temperatures iso-octane, $\lambda=1.0$ compression ratio of 6 .

With the glow-plug unheated (and a temperature of $530^{\circ} \mathrm{C}$ ) there was no pre-ignition, but when the glow-plug had a mean temperature of $800^{\circ} \mathrm{C}$ there was pre-ignition, and a bi-normal distribution has been fitted. The bi-normal distribution would suggest that the ratio of preigniting to spark-igniting cycles was 3.3 at $800^{\circ} \mathrm{C}$. However, there will be a range of preignition timings, some of which will only be just prior to the spark (leading to only slightly higher maximum cylinder pressures), and indeed surface ignition just after the spark ignition will lead to a faster burn and that too will raise the maximum cylinder pressure. So for the data with the glow-plug at a mean temperature of $800^{\circ} \mathrm{C}$ there has been a clear broadening of the distribution centred around 20 bar that has included some cycles with pre-ignition along with spark ignition, so these cycles will be counted twice (once in each distribution). 
A more direct approach is to find the mean $(\xi)$ and the standard deviation $(\sigma)$ of the distribution with no pre-ignition, and then set a threshold $\left(t_{\mathrm{PI}}\right)$ for surface pre-ignition by using a multiplying factor $x_{\text {PI. }}$ on the standard deviation

$$
t_{\mathrm{PI}}=\xi+x_{\mathrm{PI}} \sigma
$$

The results with several threshold factors $x_{\text {PI }}$ have been plotted in Figure 3 .

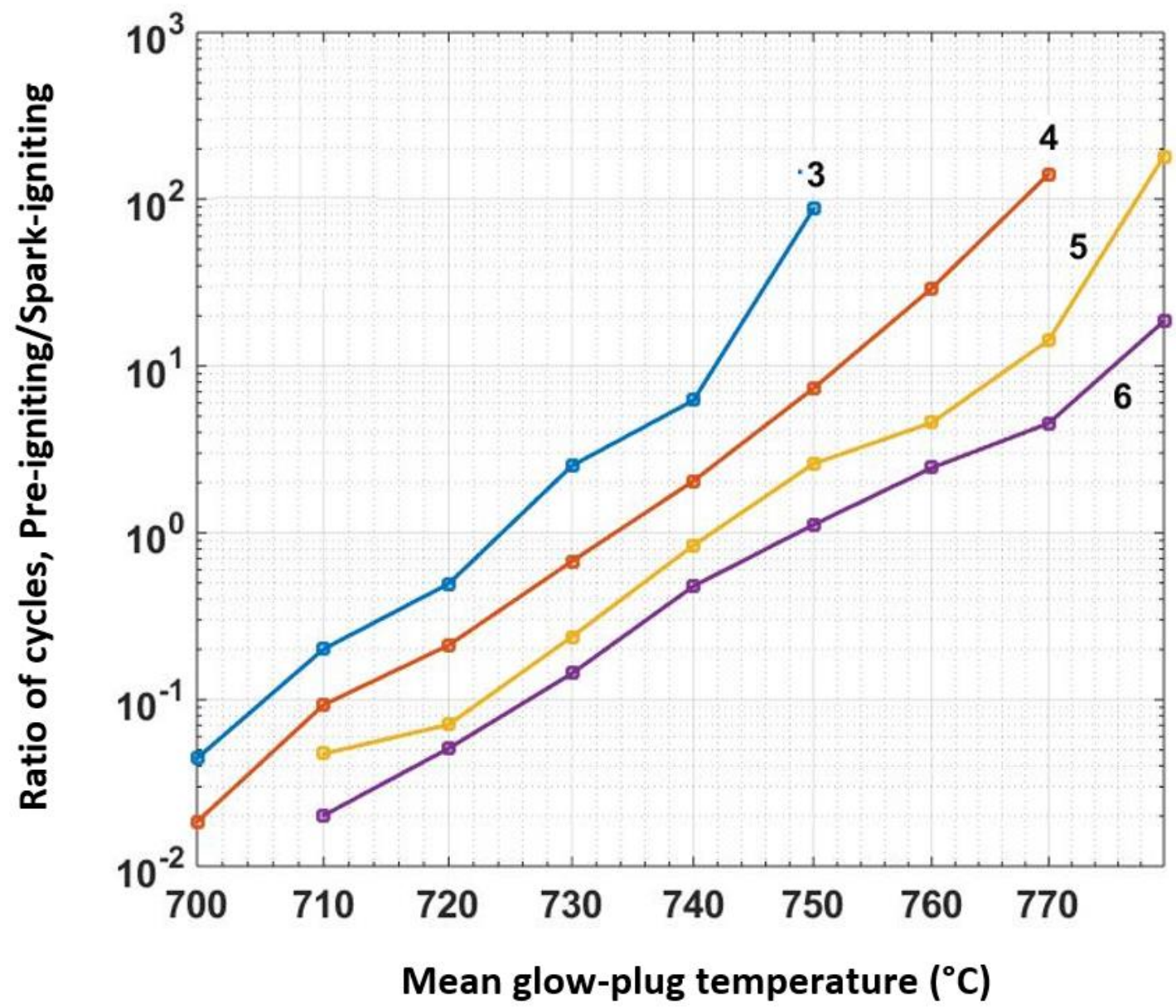

Fig 3 The effect of different threshold factors $x_{\mathrm{PI}}$ (multiples of the standard deviation as defined in Eq 1) to identify surface pre-ignition temperature thresholds; stoichiometric iso-octane; compression ratio of 6. 
As would be expected, the higher the threshold factor ( $\left.x_{\mathrm{PI}}\right)$ in Figure 3, then the higher the required glow-plug temperature for a given incidence of pre-ignition. When there are only a few either pre-igniting or spark-igniting cycles, then calculating the ratio of the pre-igniting to the spark-igniting cycles will be less accurate. The accuracy will be greatest when there is a unity ratio $\left(10^{0}\right)$ of pre-igniting to spark-igniting cycles, and Figure 3 shows that with this ratio, then the mean glow-plug temperature for pre-ignition rises with the threshold factor $\left(x_{\mathrm{PI}}\right)$ from $724^{\circ} \mathrm{C}\left(x_{\mathrm{PI}}=3\right)$ to $750^{\circ} \mathrm{C}\left(x_{\mathrm{PI}}=6\right)$. The trends plotted in Figure 3 are essentially linear, and as this is a log-linear plot, this implies that the incidence of pre-ignition has an exponential dependence on temperature.

When the glow-plug temperature is monitored on a cycle-by-cycle basis it is apparent that, although the mean temperature might be at the specified level, there are temperature variations during the cycle, and there is positive feedback from pre-igniting cycles; Figure 4. 


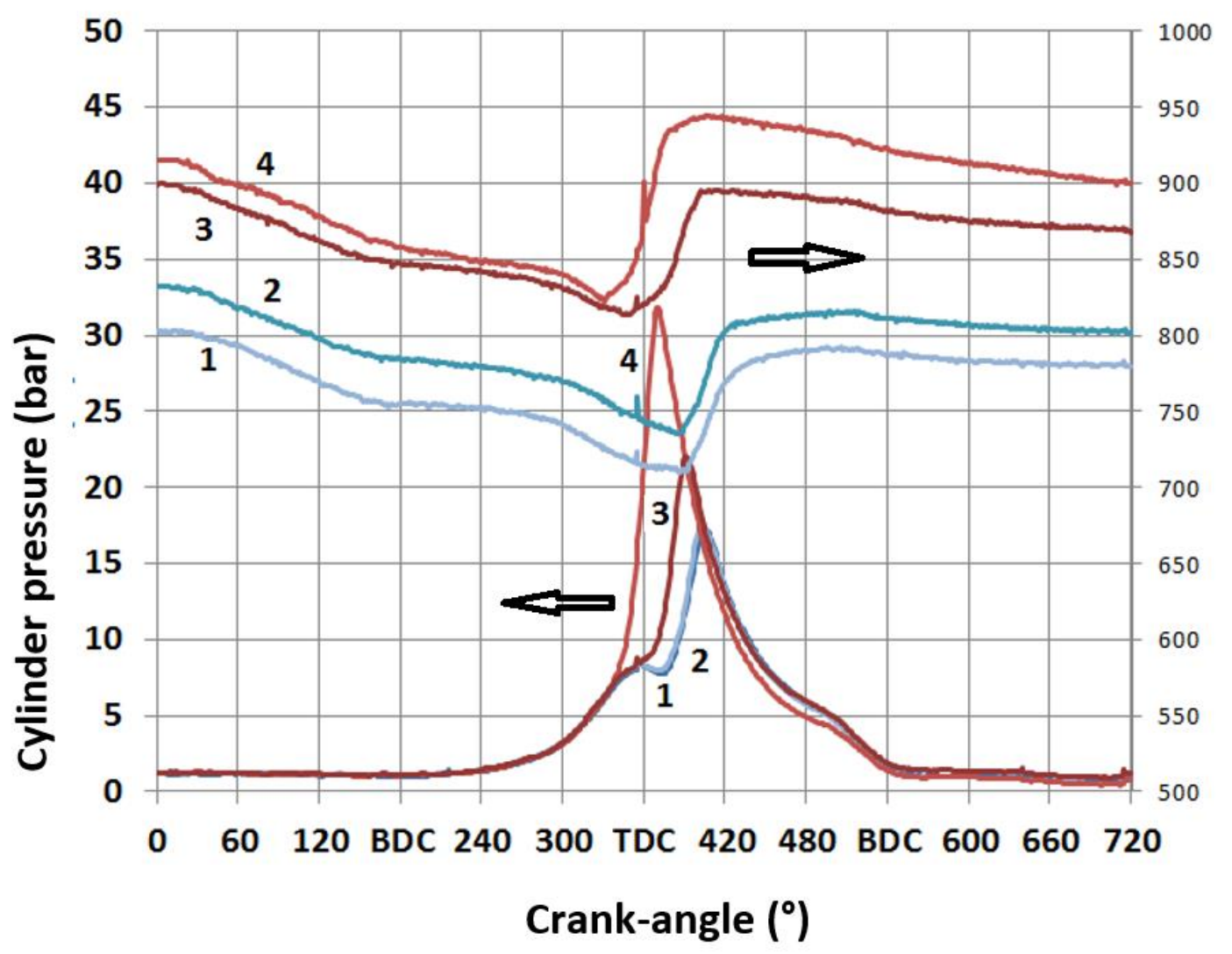

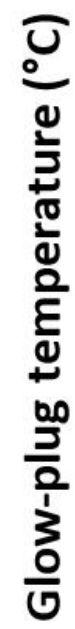

Fig 4 Pressure and temperature curves for successive spark igniting cyles $(1 \& 2)$ and successive surface pre-igniting cycles $(3 \& 4)$ with compression ratio of 6 with stoichiometric iso-octane, and a mean glow-plug temperature $\left(T_{\mathrm{GP}}\right)$ of $850^{\circ} \mathrm{C}$.

The surface pre-ignition occurred in 'waves' at intermediate temperatures - once a cycle surface pre-ignites, then a number of subsequent cycles are likely to surface pre-ignite as well, but then the engine reverts to spark-ignition. Figure 4 shows the variations in glow-plug temperature, and this suggests that using an average temperature during an experiment will lead to misleading results. To avoid this error in the glow-plug temperature a window-averaged measurement of the glow-plug temperature was formed between $\mathrm{TDC}_{\text {exhaust }}$ and $\mathrm{TDC}_{\text {firing }}$ for every cycle. 
Figure 5 shows the results from a lambda sweep, with a scatter plot showing the maximum pressure and window-averaged glow-plug temperature for every cycle with a range of different average glow-plug temperatures.

Reference cycles were recorded when the glow-plug was turned off and no surface pre-ignition was induced (these are the data blocks in Figure 5 with the lower temperatures and pressures) and are crucial for the analysis as they are used to determine the threshold for surface preignition according to Equation 1. As expected richening the mixture led to higher temperatures and pressures. Above this region sits the area of cycles which are spark-igniting while the glow-plug is hot. At these higher temperatures to the right are cycles with higher pressures that have surface pre-ignited.

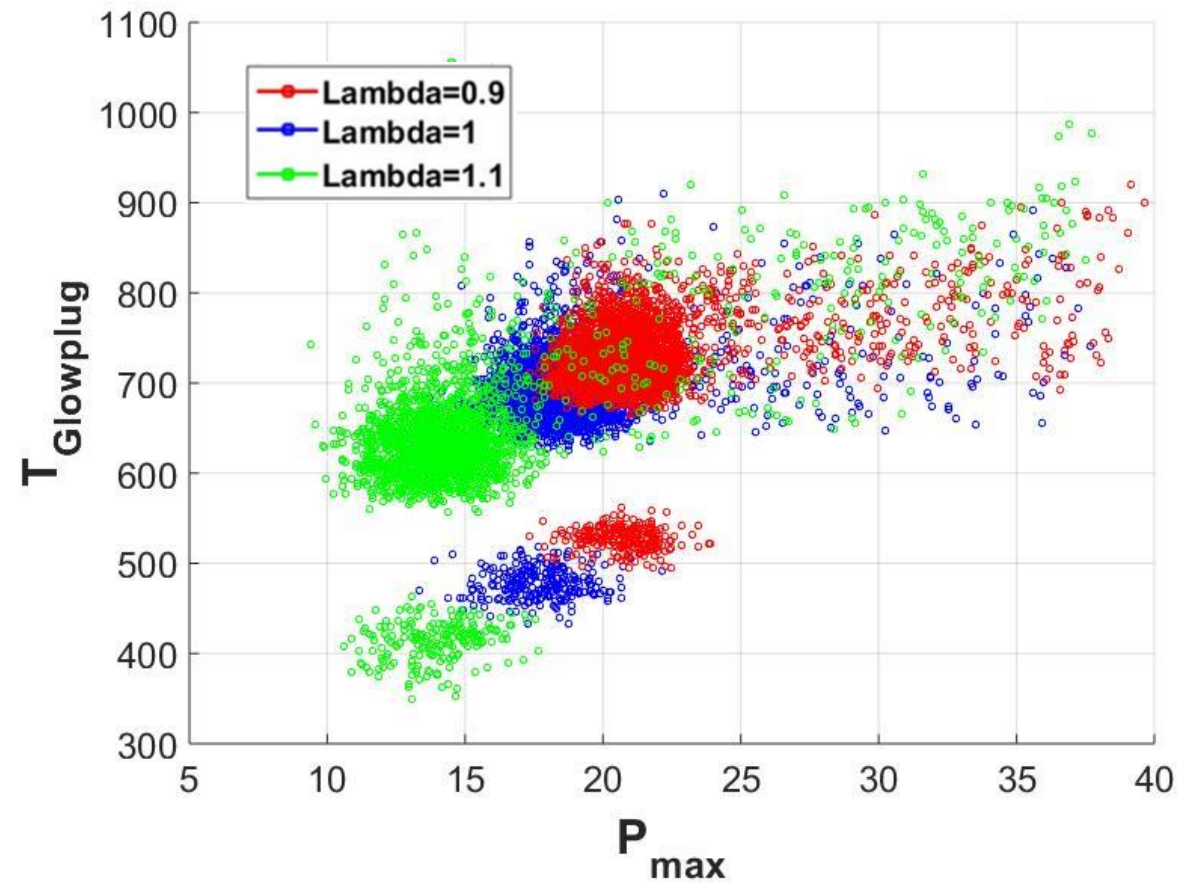

Fig 5 Window-averaged glow-plug temperatures and maximum pressure for every cycle; isooctane with a compression ratio of 6 . 
In order to form ratios of surface pre-ignition it is necessary to consider temperature bands or 'bins'. Figure 6 shows a subset of the stoichiometric data from Figure 5 with a temperature bin of $690^{\circ} \mathrm{C}$ to $710^{\circ} \mathrm{C}$, and pre-ignition pressure threshold set at 2.5 standard deviations above the mean maximum pressure value during spark ignition. Ratios can then be calculated by counting the cycles above and below the pressure for surface pre-ignition threshold.

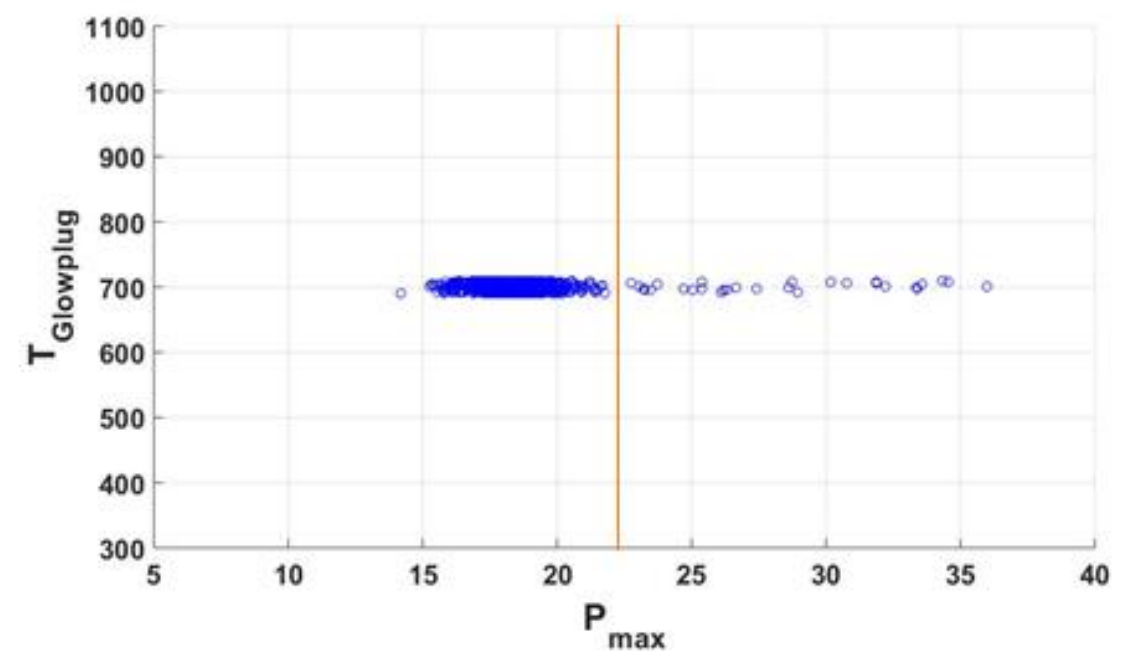

Fig 6 Subset of the window-averaged glow-plug temperatures and maximum pressure for every cycle from Figure 5 to illustrate a temperature bin of $690^{\circ} \mathrm{C}$ to $710^{\circ} \mathrm{C}$ with a surface pre-ignition pressure threshold $\left(t_{\mathrm{PI}}\right)$ of 22 bar. Stoichiometric iso-octane with $x_{\mathrm{PI}}$ $=2.5$ (Eq. 1).

To refine the method, parametric studies were conducted, to vary the width of the temperature bin, the number of cycles to be analysed, the standard deviation multiplication factor $\left(x_{\mathrm{PI}}\right)$ and the minimum number of events for a spark ignition or pre-ignition bin to be valid. Table 1 shows the range of values that were considered and the values that were selected for subsequent use. 
Table 1 Parameters used in defining the pre-ignition temperature

\begin{tabular}{lcc} 
Parameter & Range examined & Value used \\
\hline Width of the temperature bin $(\mathrm{K})$ & $5-20$ & 15 \\
Number of cycles to be analysed & $100-1000$ & 2 \\
Standard deviation multiplication factor $\left(x_{\mathrm{PI}}\right)$ & $2-6$ & \\
Minimum number of events in a spark & & 5 \\
-ignition or pre-ignition bin to be valid & $2-10$ &
\end{tabular}

\section{Surface Pre-Ignition Temperature Results}

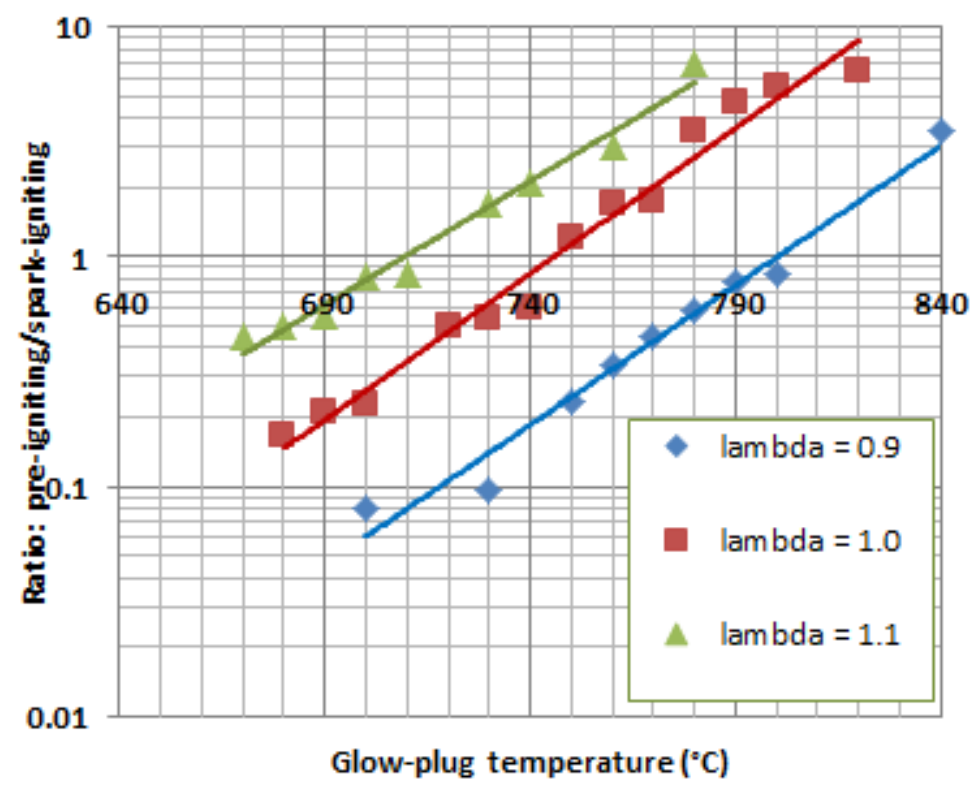

Fig 7 The influence of glow-plug temperature on the incidence of pre-ignition for a stoichiometry sweep with iso-octane and a compression ratio of 6; the straight lines are exponential fits. 
Figure 7 shows an unexpected trend - as the mixture is richened then a higher glow-plug temperature is needed for pre-ignition; the same trend was found with toluene. One explanation is that the weaker mixture will have a higher compression index (as the ratio of heat capacities will be higher), and a lower specific heat capacity. The higher compression index will mean higher compression temperatures, and the lower specific heat capacity will mean that less heat needs to be transferred from the glow-plug to further raise the mixture temperature.

This confirms the trends that have been seen before with the scatter plot data in Figure 5. This is the opposite trend to that was reported by Downs and Theobald [3].

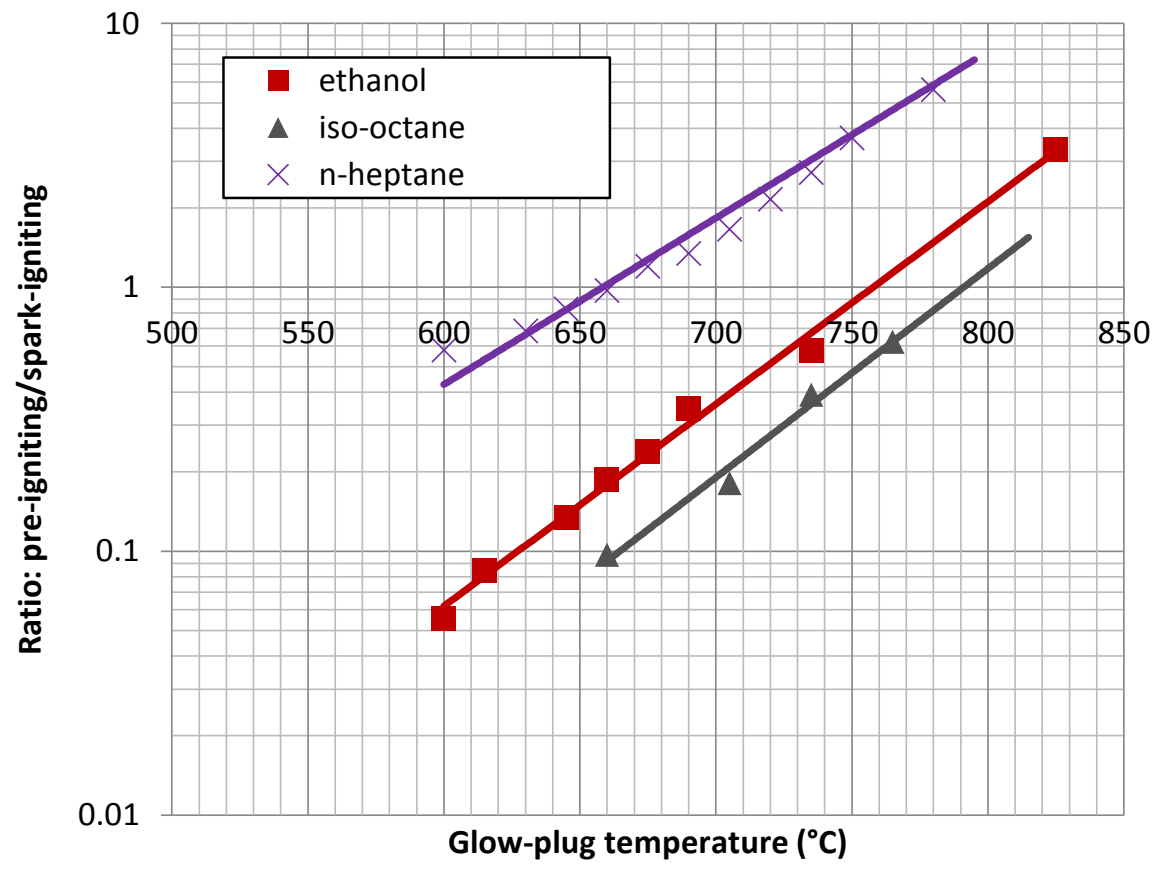

Fig 8 The influence of glow-plug temperature on the incidence of pre-ignition for stoichiometric tests; the straight lines are exponential fits; compression ratio of 5.5. 
As would be expected, Figure 8 shows that the incidence of pre-ignition increases with temperature, and the straight lines show that there is an exponential dependence on temperature. Figure 9 presents data for cyclic compounds that in general have higher preignition temperatures than the non-cyclic compounds reported in Figure 8. The aromatic compounds have higher pre-ignition temperatures than the cycloalkane, and as the length of the side chain on the aromatic increases, then the pre-ignition temperature reduces. Figure 10 compares n-pentane with iso-pentane and (as might be expected from Figure 8) the fullybranched isomer has a higher pre-ignition temperature than its straight-chain equivalent. Figure 11 shows that methanol is more susceptible to pre-ignition than ethanol.

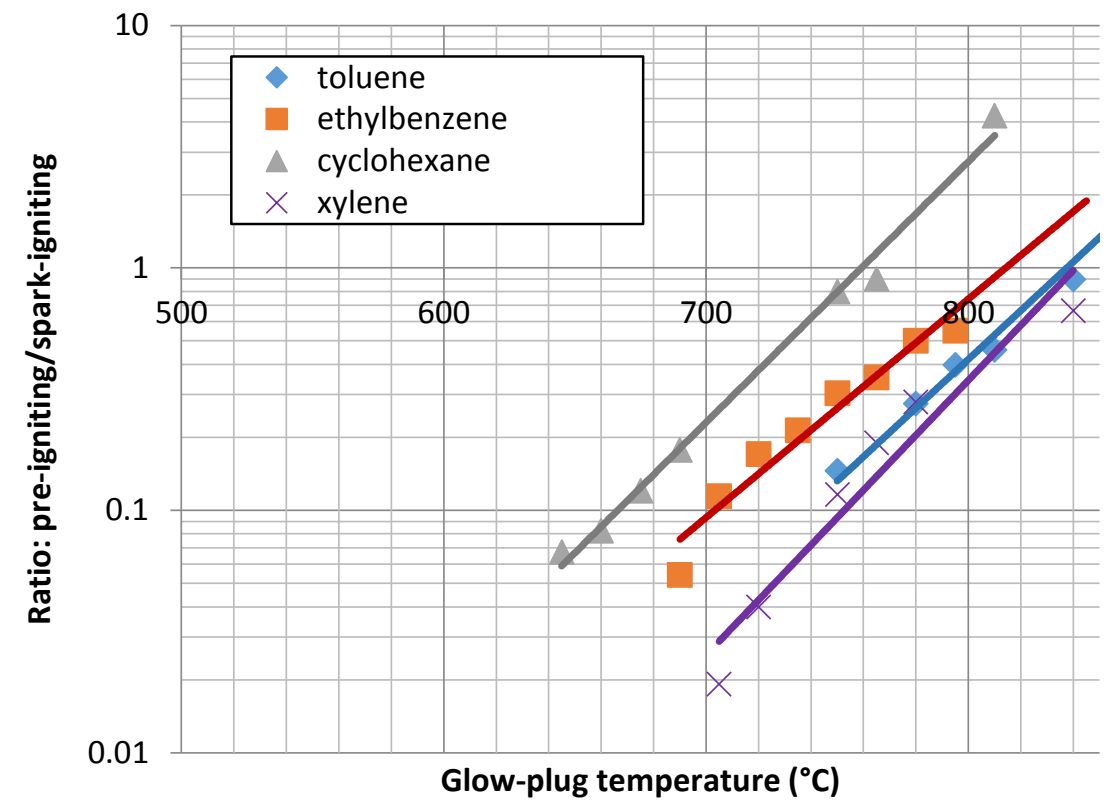

Fig 9 The influence of glow-plug temperature on the incidence of pre-ignition for stoichiometric tests of cyclic compounds; compression ratio of 5.5. 


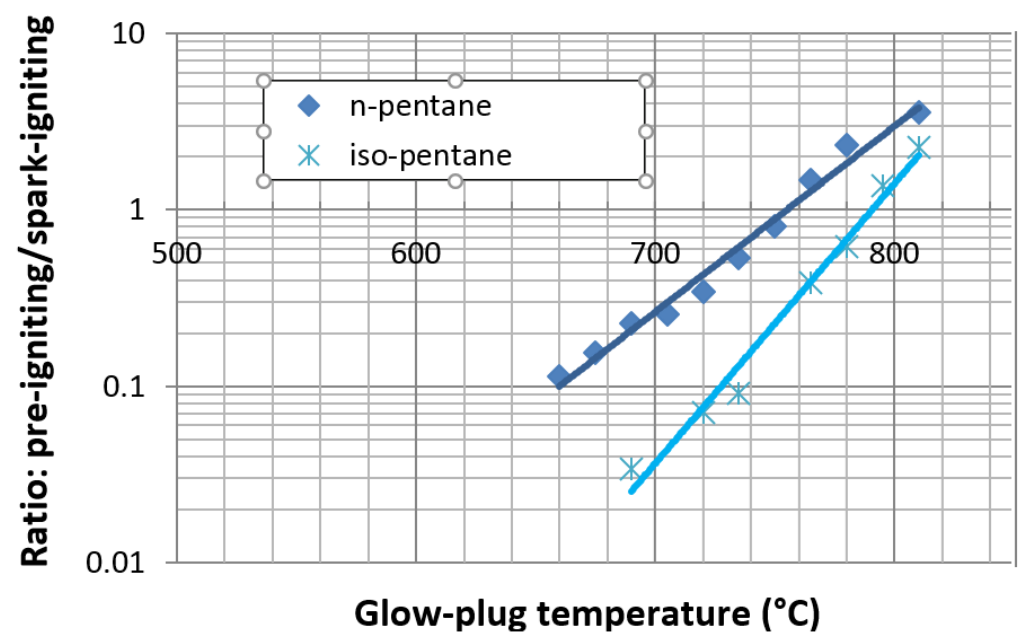

Fig 10 The influence of glow-plug temperature on the incidence of pre-ignition for stoichiometric tests of pentane isomers; compression ratio of 5.5.

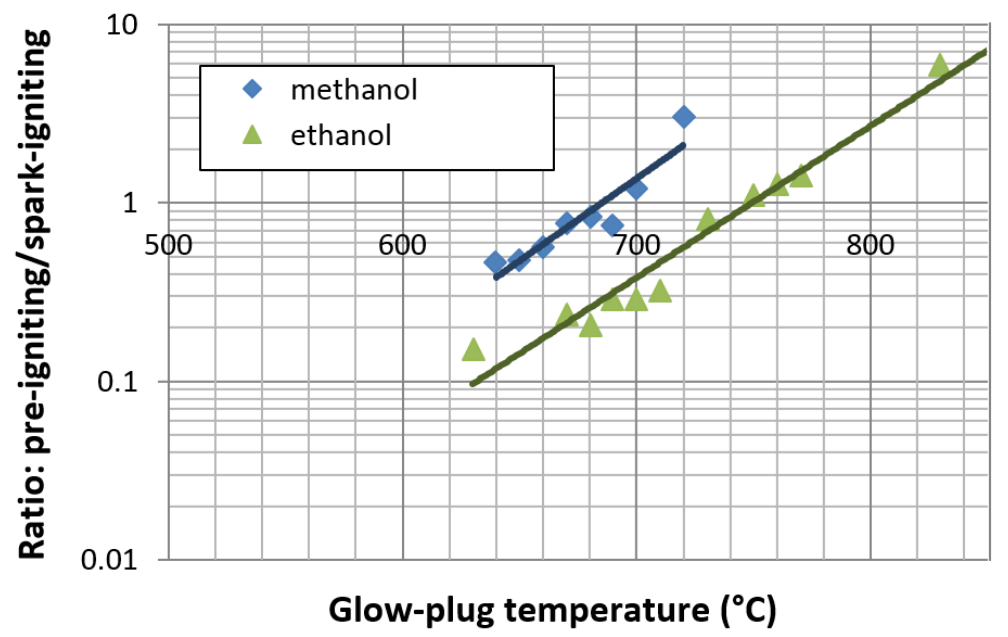

Fig 11 The influence of glow-plug temperature on the incidence of pre-ignition for stoichiometric tests of methanol and ethanol; compression ratio of 5.5.

If the unity ratio of pre-igniting to spark-igniting cycles is used to define the pre-ignition temperature, then the results are as shown in Table 2. 
Table 2 Heater temperature and octane numbers for a unity ratio of pre-igniting to sparkigniting cycles compared with the Pre-ignition Resistance (PR) of Downs and Theobald [3], also reported in [2]

\begin{tabular}{|c|c|c|c|c|c|}
\hline fuel & $\begin{array}{l}\text { Surface Pre- } \\
\text { ignition } \\
\text { Temperature } \\
\left.\text { ( }{ }^{\circ} \mathrm{C}\right)\end{array}$ & MON & RON & $\begin{array}{l}\text { Pre-ignition } \\
\text { Resistance [3] }\end{array}$ & $\begin{array}{c}\text { Heater } \\
\text { Temperature [3] } \\
\left({ }^{\circ} \mathrm{C}\right)\end{array}$ \\
\hline n-pentane & 755 & 61.9 & 62 & & \\
\hline ethanol & 758 & 89.7 & 108.6 & & \\
\hline iso-octane & 790 & 100 & 100 & 100 & 1175 \\
\hline n-heptane & 660 & 0 & 0 & & \\
\hline iso-pentane & 790 & 93 & 93.5 & 73 & 1120 \\
\hline $\begin{array}{l}\text { toluene (methyl } \\
\text { benzene) }\end{array}$ & 838 & 100.6 & 117 & 91 & 1200 \\
\hline ethyl benzene & 815 & 97.9 & 109 & 15 & 1125 \\
\hline cyclohexane & 760 & 78 & 83 & 0 & 1071 \\
\hline $\begin{array}{l}\text { xylene (Dimethyl } \\
\text { benzene) }\end{array}$ & 842 & 115 & 118 & 118 & 1165 \\
\hline
\end{tabular}

Downs and Theobald [3] reported their data (summarised here in Table 2) for conditions slightly rich $(0-10 \%)$ of stoichiometric, while the surface pre-ignition temperature in the current work is for stoichiometric operation. Downs and Theobald also noted that the heat input required for pre-ignition reduced when the compression ratio and speed were increased. The corresponding heater temperatures reported by Downs and Theobald seem very high and indeed without heating temperatures of around $900^{\circ} \mathrm{C}$ were reported. These measurements 
were from a heater that was made by butt welding a pair of thermocouple materials, and the temperature was derived by filtering the dc component from the ac heating current to find the temperature. As these results are about $300 \mathrm{~K}$ higher than the current data, a possible explanation is that the data values are in Kelvin but have been reported as Celsius.

The effect of fuel blending was analysed and results can be seen in Figure 12. The blend data in Figure 12 is for volumetric 50:50 mixtures and suggests a linear mixture rule between the volumetric based composition and the surface pre-ignition behaviour, except for the methanol and iso-octane mixture, where the addition of methanol appears to disproportionately increase the pre-ignition tendency.

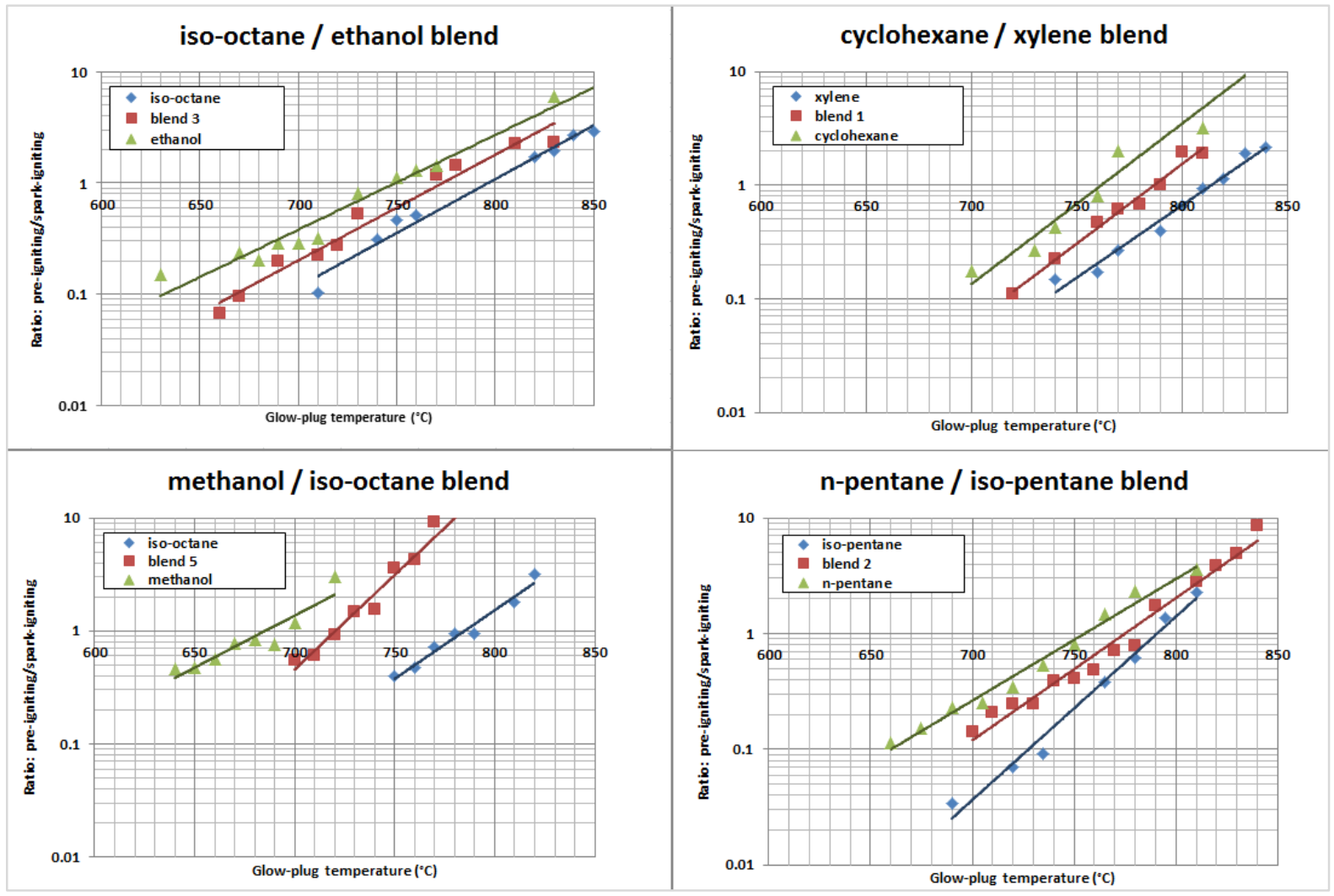

Fig 12 The influence of glow-plug temperature on the incidence of pre-ignition for stoichiometric fuel mixtures (volumetric 50:50) compared with their pure components 
at a compression ratio of 5.5. The repeat of the ethanol data shows good agreement with that plotted in Figure 8.

\section{Conclusions}

A closed loop temperature controlled glow-plug has been used in a variable compression ratio engine to control the incidence of surface pre-ignition. The in-cylinder maximum pressure has been used to obtain statistical data on the incidence of pre-ignition compared with spark ignition. The surface pre-ignition temperature has been window-averaged on a cycle-by-cycle basis with parameters that have been defined in Table 1.

A range of pure fuel components has been tested for their susceptibility to surface pre-ignition. This included six chain-structured molecules (n-heptane, ethanol, n-pentane, iso-octane and iso-pentane) and 4 ring-structured molecules (cyclohexane, ethyl-benzene, toluene and xylene). Some of these were selected as they had been tested in previous studies [3]. From these fuels, four 50:50 blends by volume were selected and also tested for their surface pre-ignition tendency.

The main findings are that:

- Alkanes and alcohols were found to be rather susceptible to surface pre-ignition

- Straight chain molecules such as n-heptane, ethanol and n-pentane have a higher preignition tendency than branched chain molecules such as iso-octane and iso-pentane.

- The pre-ignition tendency of ring-structured components depends on the length of the attached chain. Shorter side-chain molecules (xylene, toluene) are less susceptible to pre-ignition than longer side-chain molecules like ethyl-benzene; cyclohexane was more susceptible to pre-ignition than any of the aromatic fuels. 
- For three of the four fuel blends tested in this study (n-pentane and iso-pentane, cyclohexane and xylene, ethanol and iso-octane), a linear correlation between composition and surface pre-ignition tendency was observed. With methanol and isooctane the pre-ignition temperature for a 50:50 by volume mixture was closer to that of methanol than iso-octane.

- A higher glow-plug temperature is needed for pre-igniting stoichiometric or rich mixtures, and this was attributed to the weaker mixture having a higher compression index and a lower specific heat capacity. Fuel enrichment will help to inhibit preignition as well as helping to reduce exhaust temperatures and avoid thermal overload.

\section{Acknowledgements}

Funding is gratefully acknowledged from BP International for laboratory expenses and partial funding of Johannes Mutzke, who is also grateful for support from a Scatcherd European Scholarship and the EPSRC.

\section{References}

1. Wang, Z., Liu, H. and Reitz, R.D., 2017. Knocking combustion in spark-ignition engines. Progress in Energy and Combustion Science, 61, pp.78-112.

2. Ricardo H. R. , H.J.G.G., The High-Speed Internal-Combustion Engine. Vol. Fifth Edition 1968: Blackie \& Son London. 
3. Downs D., Theobald F.B., the Effect of Fuel Characteristics and Engine Operating Conditions on Pre-ignition. Proceedings of the Institution of Mechanical Engineers (Auto Division), 1963(178(2A)): p. 89-102.

4. Kalghatgi, G., Fuel/Engine Interactions. SAE 2014. ISBN 978-0-7680-6458-2.

5. Zahdeh A., R.P., Fundamental Approach to Investigate Pre-Ignition in Boosted SI-Engines. SAE International, 2011 (2011-01-0340).

6. Oguz Budak, Fabian Hoppe, Benedikt Heuser, Stefan Pischinger, Ultan Burke, and Alexander Heufer; Hot surface pre-ignition in direct-injection spark-ignition engines: Investigations with Tailor-Made Fuels from Biomass, IJER Vol 19, Issue 1, pp. 45 - 54, 2018

7. Guibet, J.C. and Duval, A., 1972. New aspects of preignition in European automotive engines (No. 720114). SAE Technical Paper.

8. Menrad, H., Haselhorst, M. and Erwig, W., 1982. Pre-Ignition and Knock Behavior of Alcohol Fuels (No. 821210). SAE Technical Paper.

9. Luef, R., Grabner, P., Eichlseder, H., Martin, C., Graf, J, and Geringer, B., 2014. Development of New Test Procedure to Determine Fuel and Oil Impact on Irregular Combustion Phenomena with Focus on Highly Boosted Downsized SI Engines. In 23 rd Aachen Colloquium Automobile and Engine Technology (pp. 1169-1204). 